\title{
Disclosing paths for multi-channel service research: A contemporaneous phenomenon and guidelines for future investigations
}

\author{
João Reis ${ }^{1}$, Marlene Amorim² ${ }^{2}$ and Nuno Melão ${ }^{3,4}$ \\ ${ }^{1}$ Department of Economics, Management and Industrial Engineering, \\ Aveiro University, Portugal \\ reis.joao@ua.pt \\ ${ }^{2}$ Department of Economics, Management and Industrial Engineering, \\ Aveiro University, Portugal \\ mamorim@ua.pt \\ ${ }^{3}$ Department of Management, School of Technology and Management of Viseu, \\ Polytechnic Institute of Viseu, Portugal,nmelao@estgv.ipv.pt \\ ${ }^{4}$ CEGE, Catholic University of Portugal (Porto), Portugal \\ nmelao@estgv.ipv.pt
}

\begin{abstract}
The present paper reports on the findings of a systematic literature review on multi-channel services. In doing so, it uses an affinity diagram to show the results of a content analysis regarding the issues addressed by the existing literature in the field. This enables to understand areas of interest in the contemporary subject of research, find gaps in the literature and, lastly, to uncover guidelines for future research. The results suggest that future investigations should focus on the integration of traditional and virtual services, on quality issues and customer behaviour towards the use of multi-channel services. Previous research also suggests that multi-channel services are largely unaddressed, regarding issues as back-office processes, within the scope of operations management. Subsequently, since multi-channel services are multidisciplinary in nature, these guidelines represent a fruitful opportunity for future research to involve other disciplines.
\end{abstract}

Keywords: Service integration, Multi-channel services, Systematic literature review 